\title{
GENERATIONAL RISK - IS IT A BIG DEAL?: SIMULATING AN 80-PERIOD OLG MODEL WITH AGGREGATE SHOCKS
}

\author{
Jasmina Hasanhodzic \\ Laurence J. Kotlikoff \\ Working Paper 19179 \\ http://www.nber.org/papers/w19179 \\ NATIONAL BUREAU OF ECONOMIC RESEARCH \\ 1050 Massachusetts Avenue \\ Cambridge, MA 02138 \\ June 2013, Revised August 2018
}

We thank Ken Judd, Thomas Sargent, Kent Smetters, Kerk Phillips, Rick Evans, Karl Schmedders, Simon Gilchrist, and Alisdair McKay for helpful comments. The views expressed herein are those of the authors and do not necessarily reflect the views of the National Bureau of Economic Research.

NBER working papers are circulated for discussion and comment purposes. They have not been peer-reviewed or been subject to the review by the NBER Board of Directors that accompanies official NBER publications.

(C) 2013 by Jasmina Hasanhodzic and Laurence J. Kotlikoff. All rights reserved. Short sections of text, not to exceed two paragraphs, may be quoted without explicit permission provided that full credit, including $\odot$ notice, is given to the source. 
Generational Risk - Is It a Big Deal?: Simulating an 80-Period OLG Model with Aggregate

Shocks

Jasmina Hasanhodzic and Laurence J. Kotlikoff

NBER Working Paper No. 19179

June 2013, Revised August 2018

JEL No. E0

\section{$\underline{\text { ABSTRACT }}$}

The theoretical literature presumes generational risk is large enough to merit study and that such risk can be meaningfully shared via appropriate government policies. This paper assesses these propositions. It develops an 80-period OLG model to directly measure generational risk and the extent to which it can be mitigated via financial markets or Social Security. The model is trend stationary as is common in the literature. It features isoelastic preferences, moderate risk aversion, Cobb-Douglas technology, and shocks to both TFP and capital depreciation. Our computation method builds on Marcet (1988), Marcet and Marshall (1994), and Judd, Maliar, and Maliar $(2009,2011)$, who overcome the curse of dimensionality by limiting a model's state space to its ergodic set.

Our baseline calibration uses the literature's estimate of the TFP shock process and sets depreciation shocks to match the variability of the return to U.S. wealth. The baseline results feature higher than observed output variability. Nonetheless, we find relatively little generational risk. This calibration produces a very small risk premium. Resolving this puzzle by adding increasing borrowing costs does not affect our conclusions regarding the size of generational risk. Our second calibration increases depreciation shocks, as in Krueger and Kubler (2006), to match the model's return variability with that of the equity market. Doing so reproduces the equity premium (even absent borrowing costs), but substantially overstates the variability of output and wages. This calibration generates significant cross-generational risk.

Under both calibrations, the one-period bond market is very effective in sharing risks among contemporaneous generations. But the simulated sizes of short and long bond positions associated with unrestricted use of this market appear unrealistically large. Finally, we find that Social Security can be effective in reducing generational risk no matter its initial size.

Jasmina Hasanhodzic

Babson College

Finance Division

231 Forest Street

Babson Park MA 02457

jhasanhodzic1@babson.edu

Laurence J. Kotlikoff

Department of Economics

Boston University

270 Bay State Road

Boston, MA 02215

and The Gaidar Institute for Economic Policy

and also NBER

kotlikoff@gmail.com 


\section{Introduction}

Generational risk references lifetime welfare differences across agents born at different dates arising from shocks to the economy. Economists have long examined generational risk and its mitigation via government policy (e.g., Diamond, 1977; Merton, 1983; Bohn, 1998, 1999, 2001, 2002, 2006, 2009; Shiller, 1999; Rangel and Zeckhauser, 2001; Smetters, 2003; Krueger and Kubler, 2006; Ball and Mankiw, 2007; and Bovenberg and Uhlig, 2008). The above studies don't directly measure the size of generational risk. Rather, they presume generational risk is large enough to merit study and show that pay-as-you-go Social Security and other generational redistribution policies can potentially share it.

This paper seeks to quantify the extent of generational risk and the relative roles of the bond market and Social Security in mitigating it. It posits an 80-period OLG model and develops a simple, robust method to overcome the curse of dimensionality, calculate the model's stationary stochastic equilibrium and measure generational risk. Our model's solution method is based on the trend-stationary, global computation techniques developed by Marcet (1988), Marcet and Marshall (1994), and Judd, Maliar, and Maliar (2009, 2011). Apart from the number of periods, our model is bare bones. It features isoelastic preferences, moderate risk aversion, Cobb-Douglas production, a one-period bond market, and aggregate shocks to both total factor productivity (TFP) and the rate of capital depreciation. Policy is limited to Social Security.

Generational risk is measured in two ways. First, we examine the dispersion across generations born at different dates in their realized levels of lifetime utility. Second, we consider the scope for contemporaneous generations to share risk. We consider two calibrations labeled baseline and alternative. The baseline calibration sets the variability of depreciation shocks to reproduce the variability of the economy's return to wealth. Specifically, we use data from the Bureau of Economic Analysis' National Accounts and the Federal Reserve's Financial Accounts to back out the return to the economy's wealth based on

$$
r_{t}=\frac{W_{t+1}-W_{t}+C_{t}-E_{t}}{W_{t}},
$$

where $W_{t}, E_{t}, C_{t}$, and $r_{t}$ stand for time-t wealth, labor income, economy-wide consumption, and the rate of return on economy-wide wealth. The wealth data come from the Federal Reserve. The labor income and consumption data are from the National Accounts. ${ }^{1}$ Some

\footnotetext{
${ }^{1}$ We measure total labor income assuming labor's share of proprietorship and partnership income is the
} 
components of the Federal Reserve wealth series are carried at books. Consequently, our $r_{t}$ series may exhibit too little variability. As an alternative, we calibrate our depreciation shocks such that our model's return volatility matches that of the equity market.

Under our baseline calibration, generational risk is small or very small according to both measures. The average, taken across all newborn generations, of the compensating differential (calculated as a generation-specific uniform absolute annual percentage consumption adjustment) needed to achieve the average, across all newborns, in realized lifetime utility is less than 5 percent. The average annual compensating differential needed to achieve full risk sharing among contemporaneous generations is less than 1 percent. Under our alternative calibration, these two figures are 21 percent and 4 percent, respectively.

Our baseline calibration features roughly 70 percent more output volatility than observed in the economy. But the risk premium is very small. However, adding one ingredient to the model, namely increasing costs of borrowing (soft borrowing constraints), leads to a realistic risk premium and Sharpe ratio. Constantinides, Donaldson, and Mehra (2002) were the first to use borrowing constraints (hard ones) in a life-cycle model to produce reasonablysized risk premiums. Our implementation borrows from Hasanhodzic (2014) who implements Constantinides et al.'s idea via soft borrowing constraints in a model like ours. ${ }^{2}$ Adding soft borrowing constraints has little impact on the economy's key macro variables and does not change our conclusions regarding the size of generational risk. Our alternative calibration produces a realistic equity premium - close to 5 percent - with no need for borrowing costs. But the model's output volatility is over 6 times too large.

We prefer the base calibration for three reasons. First, output is not excessively volatile. Second, we can generate a realistic equity premium by including borrowing costs rather than relying on excessive shocks. And third, the baseline calibration matches the return volatility on our best, if imperfect measure of aggregate wealth, not just the stock market.

The intuition for our finding of very modest generational risk among contemporaneous generations, under both calibrations, is partly that pointed out by Bohn (2009) and Bovenberg and Uhlig (2008) namely that shocks are correlated across overlapping generations. Both the young and old earn more or less income when TFP shocks hit. As for depreciation shocks, they impact young workers as well as old retirees since less capital means a lower wage. $^{3}$

same as for national income.

${ }^{2}$ Soft borrowing constraints are also featured in the theoretical models of Altonji and Siow (1987), Milde and Riley (1988), Wirjanto (1995), Fernandez-Corugedo (2002), and Chatterjee, Corbae, Nakajima, and Ríos-Rull (2007).

${ }^{3}$ With depreciation shocks, returns to capital at time $t$ and wages at time $t+1$ (not time $t$ ) are correlated since it takes a period for the change in the stock of capital to influence the wage. 
This said, the risks facing contemporaneous generations are far from perfectly correlated. Younger generations are hurt more by adverse TFP shocks than older generations whose relatively large holdings of capital are not impacted. And older generations are hurt more by adverse capital depreciation shocks than are younger generations who hold limited amounts of capital.

The different risk exposures of contemporaneous young and old generations lead them to share risk via the model's bond market. Indeed, we find that an unfettered bond market is highly effective in sharing risk among overlapping generations. However, the absolute sizes of the generation-specific short and long positions generated by the model are unrealistically large.

Like Krueger and Kubler (2006) (KK), we find that Social Security can significantly reduce generational risk regardless of its initial size. Their excellent paper may come closest to ours. They, like we, calibrate an OLG model that considers generational risk. But they provide no direct measures of generational risk nor do they examine the ability of a bond market or a Social Security system to impact such measures. Instead, they ask whether Social Security's ability to mitigate generational risk (first pointed out by Merton, 1983) can effect a Pareto improvement even if the system is unfunded and crowds out capital. ${ }^{4}$

KK's model differs from ours in important ways. First, their model posits only 9 periods. Ours has 80 . The extra number of periods appears important to the assessment of generational risk, since more periods permits better averaging of shocks over the life cycle. Additional periods also provide agents with far more opportunities to adjust their behavior (i.e., to self insure) through time. Second, KK posit Epstein-Zin preferences, whereas our preferences are isoelastic. Third, and most important, KK calibrate their depreciation shocks to the variability of the return to U.S. equities rather than to the variability of the return to aggregate U.S. wealth. The former is over six times larger than the latter. As indicated, we consider both calibrations.

We proceed below by reviewing some of the computation literature, detailing our model, describing its solution, assessing its precision, specifying its calibration, presenting results, and concluding. In the Appendix we 1) detail our algorithm, 2) present a generational risk-inducing policy to check whether our generational risk measures are indeed capturing generational risk, and 3) conduct a sensitivity analysis to consider cases with more persistent TFP shocks and very high levels of risk aversion.

\footnotetext{
${ }^{4}$ Their general conclusion, which is no, tells us that Social Security's risk mitigation is too small to overcome its crowding out effects. But this doesn't necessarily tell us anything about the size of generational risk.
} 


\section{Computation Literature Review}

OLG models with macro shocks and long-lived agents encounter the curse of dimensionality. Krussel and Smith (1998) banish the curse for certain single-agent models. They show that the state space in such models may be adequately approximated by sufficient statistics, such as the size of the economy's capital stock. Gourinchas (2000), Storesletten, Telmer, and Yaron (2007), and Harenberg and Ludwig (2016) apply the Krusell and Smith approach to OLG models. They find it works well for their purposes. But Krueger and Kubler (2004) argue that Krusell and Smith's low-dimensional approximation approach cannot, as a general matter, adequately handle OLG economies - a robustness concern raised by Krusell and Smith (1998) themselves. ${ }^{5}$

Krueger and Kubler $(2004,2006)$ represents another major milestone in battling the curse. They calculate solutions for life-cycle models experiencing macro shocks. They do so by applying Smolyak's (1963) algorithm to efficiently choose grid values. ${ }^{6}$ This algorithm guarantees uniform approximation over a small (sparse) set of points in the multidimensional hypercube. Their technique considers economic behavior over the entire state space. Unfortunately, it cannot overcome the curse at least in computing models with realistic lifespans measured in years. Indeed, Krueger and Kubler (2006) limit their model to 9 periods for computational feasibility.

Ríos-Rull $(1994,1996)$ uses local perturbation methods to solve large-scale (55-period) OLG models subject to aggregate productivity shocks calibrated to U.S. aggregate wealth as in our base model (recall that we also consider larger shocks and use a global rather than a local solution method). His papers ask, in part, whether the degree of completeness in risk-sharing arrangements materially affects aggregate variables in the economy. His answer is no. He also finds a very small risk premium, which he interprets as evidence of little macro risk. Our findings are similar in some ways and different in others. First, we find a small risk premium in our baseline simulation, but not under our alternative calibration, which produces a realistic premium. Second, like Ríos-Rull, we find that fluctuations in macro variables are similar regardless of the presence of a bond market or Social Security. But, third, under both of our calibrations, the bond market materially reduces an aggregate risk, namely generational risk. Social Security also materially reduces aggregate risk, especially under our alternative calibration. Hence, we find that risk-sharing arrangements can matter,

\footnotetext{
${ }^{5}$ In the first draft of this paper, we suggested the inability of a single statistic, namely the stock of wealth, to adequately capture consumption behavior in our OLG model by showing that transferring wealth from the young to the old would dramatically change the economy's transition. This said, multiple statistics might adequately capture the impact of such a policy.

${ }^{6}$ Malin, Krueger, and Kubler (2011) detail this method.
} 
at least for risk sharing.

Our means of dispelling the curse builds on the Generalized Stochastic Simulation Algorithm (GSSA) developed by Judd, Maliar, and Maliar (2009, 2011). GSSA, in turn, builds on the Parametrized Expectations Approach (PEA) developed by Marcet (1988), Marcet and Marshall (1994), and Marcet and Lorenzoni (1998), notably by replacing the Monte Carlo integration method employed in these studies with a more accurate Gaussian quadrature method.

Marcet (1988) is seminal. It contains the fundamental insight that, for computational purposes, the state space can be limited to the economy's ergodic set. I.e., economic behavior needs to be calculated only for states the economy will actually visit with non-trivial probability.

As indicated in Marcet and Marshall (1992) and Judd, et. al. (2009, 2011), PEA and its enhancement, GSSA, have been used to solve a wide range of economic models featuring infinitely-lived agents. Our paper appears to be the first large-scale OLG model to implement as well as build on PEA/GSSA.

Our solution method, detailed in the Appendix, is simple and can be easily extended to handle more complex OLG models. First, we draw a sequence of aggregate shocks. Second, we guess consumption functions for each of our 80 generations as linear polynomials of the economy's state vector. Third, we project the economy forward for 830 years from its initial conditions. $^{7}$ This involves clearing the bond market if one is assumed. Fourth, we use the model's Euler conditions to update our guessed decision functions. And fifth, we repeat steps two through four until the Euler conditions are satisfied to a high degree of precision.

Unlike the initial 2013 version of this paper, which followed Judd et al.'s $(2009,2011)$ use of assets and shocks as state variables, the state vector here consists of cash-on-hand and shocks. This change does not affect the results but renders our simulation method highly robust.

Reiter (2015) develops a method for solving multi-period OLG models. He independently chose to characterize the state vector in terms of cash-on-hand. His main focus is the computation of global higher-order approximations to medium-sized OLG models, including models with asset short-sale constraints, through an efficient implementation of quasi-Newton methods. His numerical results for six- and larger-period models include relatively large risk premiums and support our finding that generational risk is small.

Bovenberg and Uhlig (2008) show that fully funded defined benefit pensions combined

\footnotetext{
${ }^{7}$ We chose 830 years to produce roughly 10 data points per 82 consumption-function coefficients entering our polynomial approximations to the 80 generations' consumption functions. This said, all the data are used to estimate all the coefficients. Longer simulation periods produce no differences in results.
} 
with defined contribution pensions can improve the allocation of risk. Their work compliments Bohn's (1998, 1999, 2001, 2002, 2006, 2009) extensive analysis of the risk-sharing and risk-making properties of particular government policies. These authors examine stochastic two-period OLG models, which they solve using log-linearization techniques to derive insights into the linearized behavior around the steady state.

\section{The Model}

Our model is intentionally bare bones to maximize the potential for generational risk. Thus, we omit variable labor supply, which helps cohorts self insure against macro shocks. We also omit progressive income taxation, which redistributes, in part, from winning to losing generations. And we ignore all social insurance programs other than Social Security.

Each agent works through retirement age $R$, dies at age $G$, and maximizes expected lifetime utility. There are no short sale constraints, but in some versions of the model agents face borrowing costs which are increasing at the margin in the amount borrowed. There are also no adjustment costs, so firms maximize static profits.

\subsection{Endowments and Preferences}

The economy is populated by $G$ overlapping generations that live from age 1 to age $G$. All agents within a generation are identical and are referenced by their age $g$ at time $t$. Each cohort supplies $\ell_{g}$ units of labor per period, which equals 1 before and 0 after retirement. Hence, total labor supply equals $R$. Utility in a given year is time-separable and isoelastic, with risk aversion coefficient $\gamma$. Thus,

$$
u(c)=\frac{c^{1-\gamma}-1}{1-\gamma} .
$$

\subsection{Technology}

Production is Cobb-Douglas with output $Y_{t}$ given by

$$
Y_{t}=z_{t} K_{t}^{\alpha} L_{t}^{1-\alpha}
$$


where $z$ is total factor productivity, $\alpha$ is capital's share, $K_{t}$ is capital, and $L_{t}$ is labor demand. Equilibrium factor prices satisfy

$$
\begin{aligned}
& w_{t}=z(1-\alpha)\left(\frac{K_{t}}{R}\right)^{\alpha}, \\
& r_{t}=z \alpha\left(\frac{K_{t}}{R}\right)^{\alpha-1}-\delta_{t}
\end{aligned}
$$

with depreciation shock, $\delta_{t} \sim \mathcal{N}\left(0, \psi^{2}\right)$.

Total factor productivity, $z$, obeys

$$
\ln \left(z_{t+1}\right)=\rho \ln \left(z_{t}\right)+\epsilon_{t+1}
$$

where $\epsilon_{t} \sim \mathcal{N}\left(0, \sigma^{2}\right)$.

\subsection{Financial Markets}

Households save and invest in either risky capital or one-period safe bonds. Investing 1 unit of consumption in bonds at time $t$ yields $1+\bar{r}_{t}$ units of the model's single good in period $t+1$. The return, $\bar{r}_{t}$, is indexed by $t$ because it is determined at $t$. The asset demand of a household age $g$ at time $t$ is given by $\theta_{g, t}$ and its share of assets invested in bonds is given by $\alpha_{g, t}$. The supply of capital in period $t, K_{t}$, satisfies

$$
K_{t}=\sum_{g=1}^{G} \theta_{g, t-1}
$$

Bonds are in zero net supply, hence for all $t$,

$$
\sum_{g=1}^{G} \alpha_{g, t} \theta_{g, t}=0
$$

As shown in Green and Kotlikoff (2008), fiscal policy can be labeled in an infinite number of ways to produce whatever time path of explicit and implicit debts the government wishes to report. Such relabeling makes no difference to this or any other neoclassical model. ${ }^{8}$

\footnotetext{
${ }^{8}$ I.e., all relabeled models are isomorphisms.
} 
Hence, our model can be viewed as including government debt or not depending on the reader's preferences. With government debt included in the policy's labeling, the left-handside of (8) would be larger by the amount of debt. But the right-hand-side would also be larger by exactly the same amount, leaving the capital stock unchanged. ${ }^{9}$

How can a one-period bond market among the living impact generational risk? It obviously can't be used to share risk between the living and the unborn. But it can help contemporaneous generations share risks. For example, workers can hedge negative TPF shocks by buying bonds from retirees who can use the proceeds to buy stock. Retirees are in a position to sell bonds to workers because part of their resources, namely the principal of their assets, is insulated from TFP shocks. This is particularly the case for the oldest elderly who have the fewest years left to live and whose consumption is disproportionately determined by their stock of assets as opposed to the return on their assets.

Depreciation shocks reverse this logic, but to a lesser degree than one might first think. A large negative depreciation shock directly hurts retirees, who are the primary owners of capital. But, thanks to the induced shortage of capital, it also helps them by raising the rate of return over the short term. As for workers, the reduction in the stock of capital leads to a short-term reduction in their wage.

\subsection{Borrowing Costs}

We follow Hasanhodzic (2014) and model borrowing costs via a function proposed by Chen and Mangasarian (1996). The function is smooth and rising for negative bond holdings and essentially zero when bond holdings are close to zero or positive. Specifically, to borrow the amount of $\alpha \theta$ households have to pay the borrowing cost of $f(\alpha) \theta$, where

$$
f(\alpha)=0.2\left(-b \alpha-1+\frac{1}{5} \ln \left(1+\mathrm{e}^{5 b \alpha+5}\right)\right)
$$

and $b$ is a parameter described in Section 4 governing the slope of $f$. Since $f$ is increasing in bond shares $(\alpha)$, for a given level of assets $(\theta)$ the marginal borrowing cost is increasing in total amount borrowed $(\alpha \theta) .{ }^{10}$

\footnotetext{
${ }^{9}$ The ability to relabel a given model with a given generational redistribution policy so that it has whatever time-path of government debt one wishes to report does not imply that changes in generational policy have no impact. It simply implies that the size of government debt does not help measure this or any other policy.

${ }^{10}$ As explained in that paper, specifying the borrowing costs via $f(\alpha) \theta$ rather than $f(\alpha \theta)$ insures that the model remains scalable. This specification also makes economic sense. With $2 \theta$ in assets and some $\alpha$, the marginal costs would be the same as with $\theta$ in assets and that same alpha, since the extra assets could be used as collateral. This is in line with Goodfriend (2005) and Goodfriend and McCallum (2007), where
} 


\subsection{Government}

Social Security benefits are financed by a 15 percent wage tax and provided to all retirees on a per-capita basis. In the Appendix we also consider an unrealistic, risk-inducing policy to test the ability of our methods to capture generational risk. This risk-inducing policy also taxes the young and hands the proceeds to the old. But the proportion of the wages taken from the young raises steeply with the wage.

Let $H_{g, t}$ denote the tax levied on the age- $g$ household at time $t$ and let $B_{g, t}$ denote the benefit paid to the age- $g$ household at time $t$. Then

$$
H_{g, t}= \begin{cases}\tau w_{t} \ell_{g}, & \text { with Social Security Policy } \\ \mu\left(w_{t}\right) \ell_{g}, & \text { with Risk-Inducing Policy }\end{cases}
$$

where

$$
\mu\left(w_{t}\right)=a \underline{w}+\frac{b \bar{w}-a \underline{w}}{\bar{w}-\underline{w}}\left(w_{t}-\underline{w}\right)
$$

and $\underline{w}$ and $\bar{w}$ are minimum and maximum values of $w$. As described in Section 4, the parameters $a, b, \tau, \underline{w}, \bar{w}$ are chosen to exacerbate generational risk. Finally,

$$
B_{g, t}=\left(1-\ell_{g}\right) \frac{\sum_{g=1}^{G} H_{g, t}}{80-R} .
$$

collateral is as a valuable input in loan production because it enables a bank to enforce the repayment of loans with less monitoring (i.e., the greater is the borrower's collateral, the more productive is the intermediary's monitoring effort). 


\subsection{Household Problem}

At time $\mathrm{t}$, the economy's state is $\left(s_{t}, z_{t}\right)$, with $s_{t}=\left(x_{1, t}, \ldots, x_{G-1, t}\right)$ denoting the set of age-specific holdings of cash-on-hand. ${ }^{11}$

$$
\begin{aligned}
& V_{g}(s, z)=\max _{c, \theta, \alpha}\left\{u(c)+\beta \mathrm{E}\left[V_{g+1}\left(s^{\prime}, z^{\prime}\right)\right]\right\} \text { for } g<G, \text { and } \\
& V_{G}(s, z)=u(c)
\end{aligned}
$$

subject to

$$
\begin{aligned}
& c_{1, t}=\ell_{1} w_{t}-\theta_{1, t}-H_{1, t}+B_{1, t}, \\
& c_{g, t}=\ell_{g} w_{t}+\left[\alpha_{g-1, t-1}\left(1+\bar{r}_{t-1}\right)+\left(1-\alpha_{g-1, t-1}\right)\left(1+r_{t}\right)\right] \theta_{g-1, t-1}-\theta_{g, t} \\
& -\operatorname{If}\left(\alpha_{g-1, t-1} \theta_{g-1, t-1}\right)-H_{g, t}+B_{g, t}, \\
& \text { for } 1<g<G \text {, and } \\
& c_{G, t}=\ell_{G} w_{t}+\left[\alpha_{G-1, t-1}\left(1+\bar{r}_{t-1}\right)+\left(1-\alpha_{G-1, t-1}\right)\left(1+r_{t}\right)\right] \theta_{G-1, t-1} \\
& -\operatorname{If}\left(\alpha_{G-1, t-1} \theta_{G-1, t-1}\right)-H_{G, t}+B_{G, t},
\end{aligned}
$$

where $c_{g, t}$ is the consumption of a $g$-year old at time $t, I$ is an indicator variable that equals 1 if there are borrowing costs and equals 0 otherwise, $f$ is the borrowing cost function described above, and (15)-(17) are budget constraints for age group 1, those between 1 and $G$, and that for age group $G$.

\subsection{Equilibrium}

Given the initial state of the economy $\left(x_{1,0}, \ldots, x_{G-1,0}, z_{0}\right)$, the recursive competitive equilibrium is defined as follows.

Definition. The recursive competitive equilibrium is governed by the consumption functions, $c_{g}(s, z)$, the share of savings invested in bonds, $\alpha_{g}(s, z)$, factor demands of the representative firm, $K(s, z)$ and $L(s, z)$, government policy, $H(s, z)$ and $B(s, z)$, as well as the

\footnotetext{
${ }^{11}$ Note that $x_{G, t}$, the cash on hand of the oldest generation is not included in the state vector. When the depreciation shock, $\delta$, is zero, the value of $x_{G, t}$ can be inferred from the other state variables. When $\delta$ is random, this is no longer the case. Now the initial value of $x_{G, t}$ (or equivalently the initial value of $\delta$ ) is needed to fully characterize the economy's initial-period consumption vector. But we still exclude $x_{G, t}$ from the state vector because it provides no addition information about the economy's future evolution. Also, we can directly calculate $x_{G, t}$ and, thus, the consumption of the old for periods beyond the first.
} 
pricing functions $r(s, z), w(s, z)$, and $\bar{r}(s, z)$ such that:

1. Given the pricing functions, the value functions (13) and (14) solve the recursive problem of the households subject to the budget constraints (15)-(17), and $\theta_{g}, \alpha_{g}$, and $c_{g}$ are the associated policy functions for all $g$ and for all dates and states.

2. Wages and rates of return on capital satisfy (4) and (5).

3. The government budget constraint (12) is satisfied.

4. All markets clear.

5. Finally, for all age groups $g=1, \ldots, G-1$, optimal intertemporal consumption and investment choice satisfies

$$
\begin{aligned}
1 & =\beta E_{z}\left[\left(1+r\left(s^{\prime}, z^{\prime}\right)\right) \frac{u^{\prime}\left(c_{g+1}\left(s^{\prime}, z^{\prime}\right)\right)}{u^{\prime}\left(c_{g}(s, z)\right)}\right] \\
& +I \beta E_{z}\left[\left(\alpha_{g}(s, z)\left(\bar{r}(s, z)-r\left(s^{\prime}, z^{\prime}\right)\right)-f\left(\alpha_{g}(s, z)\right)\right) \frac{u^{\prime}\left(c_{g+1}\left(s^{\prime}, z^{\prime}\right)\right)}{u^{\prime}\left(c_{g}(s, z)\right)}\right]
\end{aligned}
$$

and

$$
0=E_{z}\left[u^{\prime}\left(c_{g+1}\left(s^{\prime}, z^{\prime}\right)\right)\left(\bar{r}(s, z)-r\left(s^{\prime}, z^{\prime}\right)-I f^{\prime}\left(\alpha_{g}(s, z)\right)\right)\right],
$$

where $E_{z}$ is the conditional expectation of $z^{\prime}$ given $z$.

\section{Calibration}

As indicated below, our calibration is standard.

\subsection{Endowments and Preferences}

Agents work for 45 periods and live for 80 . We set the quarterly subjective discount factor, $\beta$, to 0.99 . This implies an annual value of 0.96 for $\beta$. In the base model as well as the model with risk-inducing policy, risk aversion $\gamma$ equals 2 . In the alternative model it equals 5. With this level of risk aversion, the alternative model delivers a realistic risk premium absent borrowing costs. But, as indicated, it comes at cost, namely an overly volatile output series. 


\subsection{Technology}

\section{Base Model}

For the base model, we calibrate the TFP process, $z$, based on Hansen (1985) and Prescott (1986). ${ }^{12}$ Hansen estimates a quarterly value for the autocorrelation coefficient, $\rho$, of 0.95 and a standard deviation, $\sigma$, of the innovation $\epsilon$ ranging from 0.007 to 0.01. Prescott's (1986) estimates are 0.9 for $\rho$ and 0.00763 for $\sigma$.

Our assumed quarterly values for $\rho$ and $\sigma$ are 0.95 and 0.01 , respectively. On an annual basis they are 0.814 and 0.019 , respectively, generating a mean TFP value of 0.997 with a standard deviation of 0.033 and a coefficient of variation of 3.293 percent.

In our base model, we set the quarterly value of the standard deviation, $\psi$, of the depreciation shock, $\delta$, to 0.011 (implying an annual value of 0.045 ). ${ }^{13}$ This is higher than the 0.0052 quarterly estimate of Ambler and Paquet (1994). With this calibration of the shocks, the wage displays a standard deviation of 0.117 around a mean of 1.934 , for a coefficient of variation of 6.047 percent.

\section{The alternative model}

In the alternative model, the TFP process is calibrated as above, but the quarterly standard deviation of the depreciation shock is increased to 0.034 (implying an annual value of 0.137 ) to reproduce the Sharpe ratio of the stock market. ${ }^{14}$ This accords with the size of the standard deviation of the depreciation shock assumed by Krueger and Kubler (2006).

Empirical estimates of the historic equity premium and the standard deviation of the return on stocks - and therefore the Sharpe ratio - vary greatly depending on the time period used and the security chosen to proxy for the safe asset.

The equity premium often targeted in academic studies is 4 percent (see, e.g., Jagannathan, McGrattan, and Scherbina (2001)). This accords with Siegal's (1998) estimate based on data for the last two centuries. Mehra (2008) suggests that the historic equity premium ranges from 2 to 4 percent if an inflation-indexed, default-free bond portfolio is used as a proxy for the risk-free rate. Jagannathan, McGrattan, and Scherbina (2001) find that the equity premium has declined over time, averaging just 0.7 percent after 1970. As for the standard deviation of stock returns, Constantinides, Donaldson, and Mehra (2002)

\footnotetext{
${ }^{12}$ This TFP formuation is standard. See, e.g., Cooley and Prescott (1995), Ríos-Rull and SantaeulaliaLlopis (2010), Gomme, Rogerson, Rupert, and Wright (2005), and Judd, Maliar, and Maliar (2011).

${ }^{13}$ We interpret $Y$ (equation 3 ) as the net production function, and hence set the mean value of depreciation at zero.

${ }^{14}$ The model's Sharpe ratio is defined as the difference in mean real returns to capital and safe bonds divided by the standard deviation of the real return to capital.
} 
report a range of 13.9 to 15.8 percent. ${ }^{15}$ Combining a 4 percent equity premium and a 14 percent standard deviation of the real equity return implies an empirical Sharpe ratio of 0.286 .

Our model's alternative calibration generates a risk premium of 4.634 percent and a standard deviation of the return to capital of 13.922 percent, producing a Sharpe ratio of 0.333 . These values are in line with the historical record of measured equity returns. They also accord with the practitioner literature (see, e.g., Hasanhodzic, Lo, and Patel, 2009). Thus, in this case, a reasonable risk premium is obtained without resort to special preferences, borrowing costs or other assumptions, by simply overstating the size of the shocks facing the economy.

\section{Other Models}

In Appendix A.3, we consider variants of the base model with depreciation shocks turned off, but with more persistent or more volatile TFP processes and depreciation shocks. When the TFP process is more persistent, its autocorrelation coefficient equals 0.961 on an annual basis, which is significantly larger than the base case model's 0.815 value. Our more volatile TFP process incorporates a standard deviation of $\epsilon_{t}$ that is 5 times larger than in the base model.

\subsection{Borrowing Costs}

The borrowing costs function is calibrated so that the ratio of the marginal borrowing cost to the risk-free rate ranges from 15 to 20. Many credit card companies now charge interest rates between 15 and 25 percent. Given that the yield on 30-year TIPS is 1 percent and even lower on shorter-term TIPS, our borrowing cost ratio seems reasonable. Moreover, even those borrowers with high incomes, excellent credit, and considerable home equity, face home equity rates that can be 10 or more times higher than the one-month T-Bill rate. To achieve this ratio, the borrowing cost parameter $b$ is set to 25 in the model without Social Security and to 33 in the model with it.

\subsection{Government}

As indicated, Social Security benefits are financed via a payroll tax, $\tau$, of 15 percent. As for the risk-inducing policy, we set its parameters, $a$ and $b$, to 0.1 and 0.4 , respectively. The minimum and maximum values of $w, \underline{w}$ and $\bar{w}$, are estimated by iteratively simulating the

\footnotetext{
${ }^{15}$ This is in line with the standard deviation of the annualized returns of the S\&P500 Total Return Index over the last 22 years.
} 
model and using the minimum and maximum wage from a previous simulation until those values converge. ${ }^{16}$ The resulting tax rates range from 9.995 percent to 40.000 percent of the wage. Note that (10) and (11), together with the above choice of parameters, imply that the risk-inducing policy is countercyclical, i.e., the correlation between the net wage and $z$ is negative. ${ }^{17}$ Since this tax rate is applied to all wages and rises steeply with the wage, it transforms good times into bad time for workers and makes good (bad) times far better (worse) for retirees.

\subsection{Return to U.S. Wealth and to Safe Assets}

As indicated in the Introduction, to measure the empirical equivalent to the model's return on capital we use the national income accounting identity that $W_{t+1}=W_{t}+r_{t} W_{t}+E_{t}-C_{t}-G_{t}$, where $W_{t}$ stands for national wealth at time $t, E_{t}$ stands for labor income at time $t, C_{t}$ standards for household consumption at time $t$, and $G_{t}$ stands for government consumption at time t. We solve this identity for annual values of $r_{t}$ by plugging in values of $W_{t}$, reported in the Federal Reserve's Financial Accounts data, and $E_{t}, C_{t}$, and $G_{t}$, reported by the Bureau of Economic Analysis in the National Income Accounts. Our data for this calculation cover 1947-2015. All data were converted into real dollars using the PCE index and measured at producer prices. The share of labor earnings in proprietorship and partnership income was assumed to equal the overall share of labor income to national income on a year-byyear basis. The empirical counterpart to the model's safe rate of return is calculated as the annualized real return on one-month Treasuries from 1947-2015.

As reported in Table 1, the mean return to capital (actually, total U.S. assets) is 6.512 percent with a standard deviation of 4.886. The mean safe return is 1.083. These figures imply a Sharpe ratio of 1.111, which, as indicated below, is very close to our base model's Sharpe ratio.

\section{Solution Method and Its Precision}

Our algorithm contains outer and inner loops. The outer loop solves for consumption functions of each generation. The inner loop uses a combination of techniques from the numerical

\footnotetext{
${ }^{16}$ In starting this iteration we use the minimum and maximum wage from the no-policy model. The final minimum and maximum values of the wage are 1.492 and 1.983 . The average wage is 1.657 .

${ }^{17}$ For example, when the TFP decreases from 1.040 to 0.989 between years 778 and 779 , the net wage rises from 1.268 to 1.294. And when the TFP increases from 1.031 to 1.057 between years 747 and 748 , the net wage falls from 1.276 to 1.262 . Similar examples abound.
} 
analysis literature - Broyden, Gauss-Seidel, and Newton's method - to compute the agents' bond holdings and the risk-free rate that clears the bond market.

Recall that the state vector consists of cash-on-hand variables, $x_{g, t}$, of generations 1 through $G-1$ and exogenous shocks. Given the information at time $t$, agents decide how much of their cash on hand to consume, $c_{g, t}$. They also choose the proportion $\alpha_{g, t}$ of their savings to allocate to bonds at the prevailing risk-free rate $\bar{r}_{t}$.

The outer loop starts by making an initial guess of generation-specific consumption functions $c_{g}$ as polynomials (linear, for this paper) in the state vector and the prevailing depreciation shock. ${ }^{18}$ Next, we take a draw of the path of shocks for $T$ periods. We then run the model forward for T periods using the economy's initial condition (which corresponds to the non-stochastic steady state of the no-policy model), guessed consumption functions and the drawn shocks. I.e., we compute cash-on-hand variables at time $t+1$ using the information we have at time $t$ and the exogenous shocks at time $t+1$. Since the $\alpha$ 's and the $\bar{r}$ that are determined at time $t$ are realized at time $t+1$, their knowledge is necessary to compute cash-on-hand variables in period $t+1$.

In running the model forward, at each time $t$, we compute the agents' choice of bond shares and the risk-free rate that clears the bond market. To solve for $\bar{r}_{t}$, we use Broyden's method based on the bond-market clearing condition. This condition requires that the sum of bond holdings at time $t$ equals zero. The bond holdings at time $t$ of each agent age $g$ is $\alpha_{g, t} \theta_{g, t}$. The choice of the $\alpha_{g, t}$ 's make them functions of $\bar{r}_{t}$. Hence, for given values of the $\theta_{g, t}$ 's, the bond-market clearing condition is a function of $\bar{r}_{t}$ and can be used, via Broyden's method, to find the $\bar{r}_{t}$ that sustains market clearing.

For any given $\bar{r}_{t}$, the choice of $\alpha_{g, t}$ 's is determined by Gauss-Seidel iterations to solve the system of simultaneous $G-1$ generation-specific Euler equations governing the choices of the $G-1 \alpha$ 's for the new values of those $\alpha$ 's. Specifically, for given guesses of each agent's value of $\alpha$, other than that of agent $i$, we apply Newton's method to agent's $i$ 's Euler equation to determine the new guessed value of $\alpha$ for agent $i .^{19}$

Simulating the model forward produces the data needed to update our guessed consumption functions. Specifically, for each age group $g$ and each period $t$, we evaluate the Euler condition to determine what that age group's consumption should be in that period. This calculation is based on the derived period- $t$ state variables and the current guessed consumption functions of all agents, which enter, via their impact on the state vector of cash of hand at $t+1$, into the determination of any given age- $g$ agent's marginal utility of consumption

\footnotetext{
${ }^{18}$ Although we do not include $\delta$ as part of the theoretical state space, using it as a regressor for approximating the consumption functions proved valuable.

${ }^{19}$ Taking other unknowns as given is Gauss-Seidel.
} 
at $t+1$. The expected value is evaluated using Gaussian quadrature, as in GSSA.

Following PEA/GSSA, we then regress these time series of age-specific consumption levels on the state variables plus the depreciation shock and use the new regression estimates to update, with dampening, the polynomial coefficients of each guessed consumption function. We iterate the updating of these functions based, always, on the same draw of the path of shocks until consumption functions converge.

We evaluate the accuracy of our solutions using two methods proposed in the literatureout-of-sample deviations from the exact satisfaction of the Euler equations and the statistic proposed by Den Haan and Marcet $(1989,1993)$.

\subsection{Out-of-Sample Deviations from the Perfect Satisfaction of Eu- ler Equations}

A satisfactory solution requires that generation-specific Euler equations (18) hold out of sample. Hence, to test the accuracy of our solution, we draw a fresh sequence of 1660 sets of shocks for each simulated model. We then run the model forward for 1660 years (twice the length of the original simulation), imposing the drawn shocks, using the original consumption functions, $c_{g}$, and clearing the bond market by rerunning the model's inner loop each year as we move through time. To calculate out-of-sample, unit-free deviations from full satisfaction of the Euler equations, we form

$$
\begin{aligned}
\epsilon(s, z) & =\beta E_{z}\left[\left(1+r\left(s^{\prime}, z^{\prime}\right)\right) \frac{u^{\prime}\left(c_{g+1}\left(s^{\prime}, z^{\prime}\right)\right)}{u^{\prime}\left(c_{g}(s, z)\right)}\right]-1 \\
& +I \beta E_{z}\left[\left(\alpha_{g}(s, z)\left(\bar{r}(s, z)-r\left(s^{\prime}, z^{\prime}\right)\right)-f\left(\alpha_{g}(s, z)\right)\right) \frac{u^{\prime}\left(c_{g+1}\left(s^{\prime}, z^{\prime}\right)\right)}{u^{\prime}\left(c_{g}(s, z)\right)}\right]-1
\end{aligned}
$$

for each period in the newly simulated time path and for each generation $g \in 1, \ldots, G-1$. Finally, we compute the average, across time, of the absolute value of the deviations from these Euler equations for each generation.

Table A.1 in the Appendix reports summary statistics, across generations, of their average absolute deviations from Euler equations for each model considered. ${ }^{20}$ As indicated, in all cases these deviations are at most 0.004. And in most cases, they are zero to the third

\footnotetext{
${ }^{20}$ Note, these deviations are not Euler errors, which capture differences in period $t$ 's marginal utility and period $(t+1)$ 's realized marginal utility (properly weighted by $\beta$ and $r\left(s^{\prime}, z^{\prime}\right)$ ). Rather, they reference mistakes in satisfying the Euler equation, i.e., the discrepancy in period $t$ between the marginal utility and its properly weighted time- $t$ expectation.
} 
decimal place.

The portfolio choice equations (19) and the bond market-clearing condition (8) hold almost perfectly by construction, since the $\alpha$ 's and $\bar{r}$ that satisfying them are calculated in the inner loop with a high degree of precision. In particular, the average absolute deviations from these equations, which theoretically should equal zero, are at most 0.0005 and 0.00001 , respectively, and in most cases equal zero to the seventh decimal place.

\subsection{The Den Haan-Marcet Statistic}

An alternative precision test is provided by Den Haan and Marcet $(1989,1993)$. Taylor and Uhlig (1990) use this test to compare alternative solution methods for nonlinear stochastic growth models. We follow Taylor-Uhlig's particular implementation method.

As above, we start with a fresh draw of shocks over $\mathrm{T}$ periods and simulate the model forward based on these shocks, using the original consumption functions and clearing the bond market each period based on the inner loop technique (discussed above). We set $\mathrm{T}$ again to 1660 . Then, for each generation-specific Euler equation (18), we compute the residual, $\eta_{g}$, where $g$ references the generation's age at time $t$.

$$
\eta_{g}(t)=\beta(1+r(t+1)) \frac{u^{\prime}\left(c_{g+1}(t+1)\right)}{u^{\prime}\left(c_{g}(t)\right)} .
$$

We next regress, separately for each generation, their $1600 \eta_{g}$ values on a matrix $x_{g}$ consisting of a constant, five lags of $c_{g}$, and five lags of $z$. The predicted values of the regression equation, $\hat{a}_{g}$,

$$
\hat{a}_{g}=\left(\Sigma x_{g}(t)^{\prime} x_{g}(t)\right)^{-1}\left(\Sigma x_{g}(t)^{\prime} \eta_{g}(t)\right)
$$

are then used to construct the Den Haan-Marcet statistic $m_{g}$ as follows:

$$
m_{g}=\hat{a}_{g}^{\prime}\left(\Sigma x_{g}(t)^{\prime} x_{g}(t)\right)\left(\Sigma x_{g}(t)^{\prime} x_{g}(t) \eta_{g}(t)^{2}\right)^{-1}\left(\Sigma x_{g}(t)^{\prime} x_{g}(t)\right) \hat{a}_{g} .
$$

If the generation-specific Euler equations (18) are satisfied, then $E_{t-1}\left[\eta_{g}(t)\right]=0$ must hold. This implies that the coefficient vector, and, therefore, $m_{g}$ is zero, which is the null hypothesis. Note that our solution method does not enforce this property, so as Den Haan and Marcet (1994) point out, theirs is a challenging test. 
Under the null, $m_{g}$ is distributed as $\chi^{2}(11)$ asymptotically. Based on a two-sided test at the 2.5 percent significance level, we would fail to reject the null if $m_{g}$ lies outside the interval $(3.82,21.92)$. In Table A.2 we compute the minimum, mean, and maximum across generations of generation-specific statistics $m_{g}$ in the base and alternative models with and without Social Security. The mean across generations of the statistic is well within the acceptance interval for all four models. The same holds for the minimum value. Two of the four maximum values are slightly above the top value of the acceptance range.

\section{Results}

Turning to the results, we begin by comparing models' asset returns with those in the data, and then measure generational risk in our base and alternative models and the role of the bond market and Social Security in limiting such risk.

\subsection{Summary Statistics of Asset Returns}

Table 1 compares returns to capital and the safe bond in our model and in the data. The base model, regardless of whether it includes borrowing costs or Social Security, reproduces quite well the variability of the real return to U.S. wealth. Specifically, the standard deviation of the return to capital ranges from 4.587 percent to 4.606 percent in the model compared to 4.886 percent in the data. By contrast, the alternative model, where the standard deviation of the returns to capital equals 13.922 percent, overstates the actual return variability by almost a factor of three.

Table 1 shows that, absent borrowing costs, our base model also produces a risk-premium puzzle. The rate of return to capital averages 3.916 percent without Social Security and 4.892 percent with it, while the corresponding safe rates of return average 3.632 percent and 4.622 percent, respectively. The resulting risk premia are very small -0.285 percent without Social Security and 0.270 percent with it.

However, the puzzle is readily resolved by adding increasing costs to borrowing. Our borrowing cost function produces a risk-free rate of roughly two-tenths of one percent on average. This implies a risk premium of 3.762 percent in the model without Social Security and 4.772 percent with it. The latter is close to the 5.429 percent measured in the data.

The model's mean return to capital ranges from 3.916 percent to 4.994 percent in the model, depending, crucially on the presence of Social Security. This falls short of the 6.512 percent mean return to U.S. wealth observed in the data. But we could easily introduce additional government policies, such as government consumption financed by an income tax, 
Summary Statistics of Rates of Return

\begin{tabular}{|c|c|c|c|c|c|}
\hline & $\begin{array}{l}\text { Mean } \\
\text { Return to } \\
\text { Capital (\%) }\end{array}$ & $\begin{array}{l}\text { Mean Safe } \\
\text { Rate of } \\
\text { Return (\%) }\end{array}$ & $\begin{array}{l}\text { S.D. of } \\
\text { Return to } \\
\text { Capital (\%) }\end{array}$ & $\begin{array}{c}\text { Risk } \\
\text { Premium } \\
(\%)\end{array}$ & $\begin{array}{c}\text { Sharpe } \\
\text { Ratio }\end{array}$ \\
\hline & \multicolumn{5}{|c|}{ Base Model } \\
\hline No Social Security & 3.916 & 3.632 & 4.592 & 0.285 & 0.062 \\
\hline \multirow[t]{2}{*}{ Social Security } & 4.892 & 4.622 & 4.606 & 0.270 & 0.059 \\
\hline & \multicolumn{5}{|c|}{ Base Model With Borrowing Costs } \\
\hline No Social Security & 3.999 & 0.237 & 4.587 & 3.762 & 0.820 \\
\hline \multirow[t]{2}{*}{ Social Security } & 4.994 & 0.222 & 4.599 & 4.772 & 1.037 \\
\hline & \multicolumn{5}{|c|}{ Alternative Model } \\
\hline No Social Security & 2.640 & -1.994 & 13.922 & 4.634 & 0.333 \\
\hline \multirow[t]{3}{*}{ Social Security } & 4.414 & 0.241 & 14.032 & 4.173 & 0.297 \\
\hline & \multicolumn{5}{|c|}{ Data Based On Return to U.S. Wealth } \\
\hline & 6.512 & 1.083 & 4.886 & 5.429 & 1.111 \\
\hline
\end{tabular}

Table 1: Summary statistics of rates of return in the model and in the data.

which would crowd out capital and raise capital's return to match that of the data. ${ }^{21}$

Table 2 compares the variability of output for different variants of our model to that in the data. Following Prescott (1986), we detrend real net national product for the years 1929 through 2015 and form the standard deviation of the percent deviations from trend. Our model abstracts from growth, so we simply form the standard deviation of our model's percentage deviation of annual output from its mean. ${ }^{22}$

As the table shows, our models overstates actual output variability. For example, in the base model with Social Security and borrowing costs, the standard deviation of percentage output deviations is 5.237 percent in our model compared with 3.396 percent in the data. This suggests that the base model's finding of small generational risk cannot be attributed to an understatement of output variability. The alternative model produces a standard deviation of 21.516 percent with Social Security and 22.262 percent without it, overstating output volatility in the data by more than a factor of six.

\subsection{Generational Risk in the Base Model}

Our two generational risk measures focus on risk in a stationary, stochastic environment where policy has been in place for at least 75 years. In what follows we describe each measure and present corresponding results.

\footnotetext{
${ }^{21}$ We chose not to do so to isolate the impact of Social Security on generational risk.

${ }^{22}$ The standard deviation of detrended per capita output is virtually identical.
} 


\begin{tabular}{|c|c|}
\hline \multicolumn{2}{|c|}{$\begin{array}{l}\text { Standard Deviation of Percent Deviations of } \\
\text { Output from Trend }\end{array}$} \\
\hline Model/Data & S.D. (\%) \\
\hline \multicolumn{2}{|l|}{ Base Model } \\
\hline No Social Security & 5.782 \\
\hline Social Security & 5.685 \\
\hline \multicolumn{2}{|l|}{ Base Model With Borrowing Costs } \\
\hline No Social Security & 5.275 \\
\hline Social Security & 5.237 \\
\hline \multicolumn{2}{|l|}{ Alternative Model } \\
\hline No Social Security & 22.262 \\
\hline Social Security & 21.516 \\
\hline \multicolumn{2}{|l|}{ Data } \\
\hline Real Net National Product, 1929-2015 & 3.396 \\
\hline
\end{tabular}

Table 2: Standard deviation of percent deviations from trend of U.S. real Net National Product, 1929-2015 and standard deviation of percent deviations of output from its mean in the base and alternative models.

\subsubsection{Realized Utility Measures of Generational Risk}

In Table 3 we report the realized lifetime utility generational risk measure. The realized utility measure is based on the particular state to which the generation is born and the particular sequence of shocks it experiences over its lifetime. We first calculate each generation's particular realized lifetime utility and form the average of these realized values across all generations born between years 75 and 751. Next, we calculate for each generation the factor by which we need to multiply each year's realized consumption to produce the same realized lifetime utility as the first 677 generations experience on average. Finally, we compute the absolute value of this factor's deviation from 1 . The closer are the percent adjustments to 0 , and the less variable they are through time, the less difference does the date of birth make for the household's expected lifetime utility, i.e., the smaller is the generational risk.

This table shows that the compensating consumption differential needed to equate realized lifetime utility of each cohort through time to the average across newborns of their realized lifetimes utilities averages 4.675 percent with a standard deviation of 3.800 percent in the presence of a fully functional bond market. These values are modest. The maximum value of the differential is 19.961 percent, which is large, but as discussed above, the bond market is not designed to share risk among the living and the unborn. Rather, it may exacerbate differences in realized lifetime utility across non-overlapping generations or generations with limited overlap. 
Absolute Percentage Adjustments to Achieve

Average Realized Utility of Newborns

\begin{tabular}{lcccc}
\hline & Min & Mean & Max & S.D. \\
Bond Market \\
No Social Security & 0.014 & 4.675 & 19.961 & 3.800 \\
Social Security & 0.000 & 4.107 & 18.097 & 3.388 \\
\multicolumn{5}{c}{ Borrowing Costs } \\
No Social Security & 0.006 & 2.663 & 10.333 & 2.082 \\
Social Security & 0.001 & 2.372 & 10.639 & 1.996 \\
No Bond Market & & \\
No Social Security & 0.000 & 2.686 & 10.329 & 2.096 \\
Social Security & 0.007 & 2.394 & 10.639 & 2.006 \\
\hline
\end{tabular}

Table 3: Means, standard deviations, minimums, and maximums of absolute percent adjustments in each cohort's annual consumption needed to achieve post-transition average realized lifetime utility of newborns in the base model.

Eliminating the bond market leaves us with our purest measure of generational risk since it is the risk that prevails prior to any market or government mitigation. In this case, the average absolute percentage adjustment across 677 generations needed to achieve the same realized lifetime utility is only 2.686 percent. Clearly, this represents modest generational risk. Adding Social Security, whether in the presence or absence of bonds, does relatively little to limit the small residual risk needing to be shared. For example, with no bond market, Social Security reduces this risk measure by only 10.9 percent-from 2.686 percent to 2.394 percent.

Why might shocks hitting earlier generations not greatly impact later generations? All generations live for 80 periods meaning that initial good or bad shocks will have limited impact on the shocks that a generation experiences later in life. ${ }^{23}$ Intuitively, new shocks, even if their TFP impact persists, arrive each period and average out. Moreover, our economy is ergodic and naturally rebounds from bad or good states. Hence, a generation that is born into bad (good) times with a small (large) stock of capital will, on average, experience better (worse) times in the future.

\subsubsection{Measuring Generational Risk Among Contemporaneous Generations}

Finally, we ask whether contemporaneous generations are experiencing materially different shocks as measured by differences in their annual percentage consumption changes. If so, such

\footnotetext{
${ }^{23}$ This is true even when we assume unrealistically high degrees of autocorrelation in TFP shocks.
} 
changes could be pooled either via private arrangements or government policy. Recall that full risk sharing among contemporaneous generations, indeed all agents, with the homothetic preferences considered here, requires equal percentage changes in the consumption from one period to the next (see Abel and Kotlikoff, 1988). Hence, one can measure the extent of generational risk by considering the co-movement of consumption across age groups as well as the extent of consumption adjustments that would be needed to achieve perfect consumption co-movement.

We present results with and without Social Security, post transition. Minimum, mean, and maximum are taken across all cohorts and all time. The standard deviation value is the mean across cohorts of cohort-specific time-wise standard deviations.

\section{Absolute Percentage Adjustments to Achieve Perfect Risk Sharing Among Contemporaneous Generations}

\begin{tabular}{|c|c|c|c|c|}
\hline & Min & Mean & Max & S.D. \\
\hline \multicolumn{5}{|c|}{ No Borrowing Costs } \\
\hline No Social Security & 0.000 & 0.224 & 1.098 & 0.163 \\
\hline Social Security & 0.000 & 0.317 & 1.108 & 0.152 \\
\hline \multicolumn{5}{|c|}{ Borrowing Costs } \\
\hline No Social Security & 0.000 & 0.933 & 5.904 & 0.699 \\
\hline Social Security & 0.000 & 0.713 & 3.811 & 0.535 \\
\hline \multicolumn{5}{|c|}{ No Bond Market } \\
\hline No Social Security & 0.000 & 0.929 & 5.853 & 0.696 \\
\hline Social Security & 0.000 & 0.721 & 3.877 & 0.539 \\
\hline
\end{tabular}

Table 4: Absolute percent adjustments to achieve perfect risk sharing among contemporaneous generations in the base model. Minimum, mean, and maximum are taken across all cohorts and all time. The standard deviation value is the mean across cohorts of cohort-specific standard deviations.

Table 4 summarizes the agent- and year-specific absolute percentage consumption adjustment needed to achieve perfect risk sharing, i.e., to ensure that all agents experience the same percentage change in the year in question. ${ }^{24}$ It shows that the average (across agents) absolute percentage adjustment needed to achieve full risk sharing is 0.224 percent without Social Security, but with an unfettered bond market. The standard deviation is only 0.163 percent. Hence, generational risk among contemporary cohorts is quite small even absent any government risk-sharing policy. Indeed, the maximum absolute adjustment is only 1.098 percent. Adding Social Security to the risk-sharing mix actually slightly exacerbates generational risk, raising the average adjustment needed to achieve percent risk sharing to 0.317

\footnotetext{
${ }^{24}$ Values of 0.000 and 1.000 reflect rounding.
} 
percent.

With borrowing costs and no Social Security, the absolute adjustments are larger, but still quite small -0.933 percent on average. The maximum adjustment in this case -5.904 percent - is almost six times larger than arises without borrowing costs. In this case, adding Social Security improves risk sharing. It reduces the average absolute adjustment needed for full risk sharing by one quarter. It also lowers the standard deviation of the adjustment and its maximum value.

Note that the unfettered bond market is more than three times as efficient as Social Security in reducing risk among contemporaneous generations. Compare, in this regard, the value of 0.224 percent with the value of 0.721 percent. The former number is the mean absolute percent adjustment with the bond market, but no Social Security. The later value is the mean adjustment with Social Security, but no bond market. However, as shown below, the simulated size of short and long bond positions associated with unrestricted use of this market appears unrealistically large. ${ }^{25}$

\subsubsection{Illustrating Consumption Co-Movement Among Contemporaneous Gen- erations}

Illustrating the Comovement in Consumption

\begin{tabular}{|c|c|c|c|c|c|c|c|c|c|c|c|}
\hline Age & TPP & $\begin{array}{c}\text { Depreciation } \\
\text { Rate (\%) }\end{array}$ & C & $\begin{array}{c}\text { \% Change } \\
\text { in C }\end{array}$ & Wage & $\begin{array}{c}\text { Stock } \\
\text { Holdings }\end{array}$ & $\begin{array}{c}\text { Bond } \\
\text { Holdings }\end{array}$ & $\begin{array}{c}\text { Rate of } \\
\text { Return } \\
\text { on Bonds } \\
(\%)\end{array}$ & $\begin{array}{l}\text { Rate of } \\
\text { Return to } \\
\text { Capital } \\
\text { (\%) }\end{array}$ & $\begin{array}{c}\text { \%Change } \\
\text { Output }\end{array}$ & $\begin{array}{c}\% \text { Change } \\
\text { in Agg C }\end{array}$ \\
\hline \multicolumn{12}{|c|}{ Worker } \\
\hline 29 & 0.934 & -5.960 & 1.659 & 2.396 & 1.805 & 11.029 & -10.160 & 3.446 & 9.544 & -1.460 & 2.772 \\
\hline 30 & 0.946 & 5.160 & 1.605 & -3.276 & 1.859 & 11.916 & -10.198 & 3.284 & -1.644 & 2.959 & -3.169 \\
\hline 31 & 0.971 & 6.285 & 1.555 & -3.129 & 1.873 & 11.263 & -9.823 & 3.462 & -2.537 & 0.754 & -3.320 \\
\hline 32 & 0.984 & 7.453 & 1.494 & -3.907 & 1.858 & 10.563 & -9.430 & 3.709 & -3.492 & -0.799 & -3.907 \\
\hline 33 & 0.974 & 3.545 & 1.460 & -2.258 & 1.796 & 9.784 & -9.007 & 3.951 & 0.571 & -3.317 & -1.957 \\
\hline 34 & 0.950 & 2.733 & 1.428 & -2.227 & 1.732 & 9.521 & -8.708 & 4.009 & 1.367 & -3.544 & -1.765 \\
\hline \multicolumn{12}{|c|}{ Retiree } \\
\hline 69 & 0.934 & -5.960 & 1.700 & 3.030 & 0.000 & 20.772 & 9.111 & 3.446 & 9.544 & -1.460 & 2.772 \\
\hline 70 & 0.946 & 5.160 & 1.646 & -3.228 & 0.000 & 21.274 & 9.205 & 3.284 & -1.644 & 2.959 & -3.169 \\
\hline 71 & 0.971 & 6.285 & 1.585 & -3.670 & 0.000 & 19.847 & 8.939 & 3.462 & -2.537 & 0.754 & -3.320 \\
\hline 72 & 0.984 & 7.453 & 1.519 & -4.162 & 0.000 & 18.362 & 8.645 & 3.709 & -3.492 & -0.799 & -3.907 \\
\hline 73 & 0.974 & 3.545 & 1.490 & -1.948 & 0.000 & 16.874 & 8.293 & 3.951 & 0.571 & -3.317 & -1.957 \\
\hline 74 & 0.950 & 2.733 & 1.466 & -1.552 & 0.000 & 16.052 & 8.050 & 4.009 & 1.367 & -3.544 & -1.765 \\
\hline
\end{tabular}

Table 5: An example of consumption co-movement of a worker and a retiree through time.

\footnotetext{
${ }^{25}$ We also computed pairwise correlations of percentage changes in consumption among all contemporaneous generations. Rounded to one decimal place, all correlations equal 0.9, regardless of the bond market or Social Security. This indicates that the risk the economy experiences is, for the most part, not generationspecific.
} 
In Table 5, we follow a worker age 29 and a retiree age 69 for six years to illustrate the co-movement in their consumption in the base model. While we consider just six years, starting in the year 745, they are very typical of our simulation results.

As columns two and three show, the model's shocks are sizable. There is, for example, close to a 5 percent difference between the largest and smallest TFP values over the period. And the depreciation shocks range from -6.0 percent to 7.5 percent. (Note, negative depreciation is a good thing, i.e., a plus, when it comes to expanding the size of the capital stock and the return to capital.)

These shocks as well as their associated impact on capital accumulation produce significant changes in the wage. In year 750, for example, the wage is 6.78 percent smaller than two years earlier. And the rate of return to capital ranges from 9.54 percent in 745 to -3.49 percent in 746 .

Interestingly, aggregate consumption and output can move in different directions over short periods in our model. For example, output rises, but consumption falls between the first and second years of our table. This reflects the higher stock of capital (thanks to negative depreciation) in 745 and the higher level of TFP. But the year 746 return to capital is negative reflecting the significant depreciation rate that year. This depresses the consumption of the old as well as the young who also hold stock (capital).

The size of these shocks, the size of changes to factor returns, and the size of output changes notwithstanding, there is very high co-movement of the worker's, the retiree's consumption as well as aggregate consumption. ${ }^{26}$

Table 5 suggests that borrowing by the young and lending by the old are instrumental to risk sharing among the living. This raises the real world question of whether the young borrow to buy stocks.

We have two responses. First, as shown below, eliminating the bond market actually reduces risk across non-contemporaneous generations, although at the price of a modest rise in risk across contemporaneous generations.

Second, one subtle mechanism by which workers may be borrowing from the old to purchase stocks is via their company's borrowing on their behalf and paying them more when the company does well. These payments may be contemporaneous with company's performance or be made through time. This effectively lets workers borrow to invest in stocks. $^{27}$

That said, the simulated sizes of short and long bond positions associated with unre-

\footnotetext{
${ }^{26}$ Also per capital consumption since the model features zero population growth.

${ }^{27}$ The fact that young borrow to purchase equity is a central feature of Constantinides, Donaldson, and Mehra (2002).
} 
stricted borrowing and lending appear unrealistically large.

\subsection{Generational Risk in the Alternative Model}

\subsubsection{Realized Utility Measures of Generational Risk}

Table 6 reports our realized lifetime utility measures in the alternative model. The measures are much larger that their Table 3 counterparts. For example, under the alternative calibration with neither bonds nor Social Security, one would need to expand or contract a newborn's consumption in all years of her life by 15.141 percent, on average, in order to achieve average realized utility across newborns. The maximum adjustment is 83.694 percent. The corresponding figures in the base model are 2.686 percent and 10.329 percent. Thus, the alternative calibration is highly effective in generating risk across newborns through time. ${ }^{28}$

\begin{tabular}{|c|c|c|c|c|}
\hline \multicolumn{5}{|c|}{$\begin{array}{c}\text { Absolute Percentage Adjustments to Achie } \\
\text { Realized Utility of Newborns } \\
\text { Alternative Model }\end{array}$} \\
\hline & Min & Mean & Max & S.D. \\
\hline \multicolumn{5}{|c|}{ Bond Market } \\
\hline No Social Security & 0.096 & 20.078 & 78.201 & 16.675 \\
\hline Social Security & 0.008 & 16.895 & 66.167 & 14.229 \\
\hline \multicolumn{5}{|c|}{ No Bond Market } \\
\hline No Social Security & 0.105 & 15.141 & 83.694 & 13.758 \\
\hline Social Security & 0.004 & 9.248 & 32.863 & 8.435 \\
\hline
\end{tabular}

Table 6: Means, standard deviations, minimums, and maximums of absolute percent adjustments in each cohort's annual consumption needed to achieve post-transition average realized lifetime utility of newborns in the alternative model.

Table 6 confirms that the presence of the bond market increases generational risk. However, in the alternative model, the increase is much more pronounced.

\subsubsection{Measuring Generational Risk Among Contemporaneous Generations}

Table 7 presents our measures of generational risk among contemporaneous generations for the alternative model. As indicated, the average absolute percentage adjustments needed to

\footnotetext{
${ }^{28}$ These results raise the question of whether Krueger's and Kubler's (2006) finding that Social Security can be Pareto improving, if not in general, at least under some under particular preference structures, is driven by their assumption of unrealistically large economic shocks.
} 
achieve full risk sharing are less than half a percent without Social Security, but with bonds. Hence, in the presence of a bond market, generational risk among contemporary cohorts is quite small even absent any government risk-sharing policy. Indeed, the maximum value is only 7.014 percent. Adding Social Security reduces reduces these small values even further. Now the average absolute adjustment is 0.262 percent and the maximum adjustment is 4.172 percent.

\section{Absolute Percentage Adjustments to \\ Achieve Perfect Risk Sharing Among Contemporaneous Generations Alternative Model}

\begin{tabular}{|c|c|c|c|c|}
\hline & Min & Mean & Max & S.D. \\
\hline \multicolumn{5}{|c|}{ Bond Market } \\
\hline No Social Security & 0.000 & 0.437 & 4.557 & 0.341 \\
\hline Social Security & 0.000 & 0.296 & 4.179 & 0.289 \\
\hline \multicolumn{5}{|c|}{ No Bond Market } \\
\hline No Social Security & 0.000 & 3.473 & 24.012 & 2.627 \\
\hline Social Security & 0.000 & 2.307 & 17.919 & 1.789 \\
\hline
\end{tabular}

Table 7: Absolute percent adjustments to achieve perfect risk sharing among contemporaneous generations in the alternative model. Minimum, mean, and maximum are taken across all cohorts and all time. The standard deviation value is the mean across cohorts of cohort-specific standard deviations.

Without bonds or Social Security, the absolute adjustments are larger - 2.943 percent on average, with a much larger maximum value of 23.983 percent. Social Security reduces the average and the maximum values of the adjustment to 2.004 percent and 15.335 percent, respectively.

But, as was the case in the base model, if the bond market could be used with unrestricted leverage, it would be more effective than Social Security in reducing generational risk among the living. To see this, compare the value of 0.486 percent with the value of 2.004 percent. The former value is the mean absolute percent adjustment with the bond market, but no Social Security. The later value is the adjustment with Social Security, but no bond market.

\section{Conclusion}

Generational risk and its mitigation via Social Security and other government policies has long intrigued economists. This paper adds to the literature on this issue. Its bare bones, trend-stationary, 80-period OLG model can generate small or large generational risk depending on the calibration. 
Our baseline calibration sets depreciation shocks to replicate the variability of returns to total U.S. wealth. Our alternative calibration reproduces the variability of returns to U.S. equities. We view the baseline calibration as more reasonable, since its output (and thus wage) variation, while higher than observed, is substantially lower than that of the alternative calibration.

Under the baseline calibration, generational risk is remarkably small, regardless of the presence of the bond market. This holds whether generational risk is measured in terms of differences across age cohorts in realized lifetime utility or as differences across contemporaneous generations in their exposure to risk from contemporaneous shocks. Under our alternative calibration, the risk of realizing a much higher level of lifetime utility than another generation is economically significant. However, even with this calibration, contemporaneous generations are able to effectively trade risk using the model's one-period bond market with unrestricted leverage. Interestingly, though, although the bond market helps contemporaneous generations share risk, its presence accentuates differences in realized lifetime utility across generations.

Social Security is a significant generational risk-mitigating institution regardless of the calibration. But it's not as powerful in this regard as the one-period bond market. One should, however, view our bond-market results as illustrative of the potential power of financial exchange to share risk, not as evidence that such risk sharing necessarily arises. The reason is that full financial risk sharing entails, in our model, unrealistically large short- and long-bond positions for particular cohorts.

Beyond these points, the paper demonstrates the feasibility of simulating realistic, largescale OLG models with aggregate shocks in which generational policy matters as appears so evident in real economies. Our solution algorithm is simple and results are robust based on a range of simulations including those featuring large and persistent TFP shocks as well as very high degrees of risk aversion. An interesting direction would be to move away from our trend stationary environment and consider the effect on generational risk of a random walk in TFP in this model. This is likely more important for studying generational risks in countries whose TFP processes exhibit either much higher serial correlation than observed for the U.S. or breaks in their TFP growth rates. ${ }^{29}$ We leave this for future work.

\footnotetext{
${ }^{29}$ Prescott(1986) indicates that modeling the growth rate in U.S. TFP as a random walk "result in essentially the same fluctuations" as the autoregressive process, which he used and we employ. This said, generational risk, even in the U.S., might be different based on a random walk in TFP growth.
} 


\section{References}

Abel, A. and L. J. Kotlikoff, 1988, "Does the Consumption of Different Age Groups Move Together? A New Nonparametric Test of Intergenerational Altruism", NBER Working Papers 2490, National Bureau of Economic Research.

Altonji, J. G. and A. Siow, 1987, "Testing the Response of Consumption to Income Changes with (Noisy) Panel Data", Quarterly Journal of Economics 102, 293-328.

Ambler, S. and A. Paquet, 1994, "Stochastic Depreciation and the Business Cycle", International Economic Review 35, 101-116.

Auerbach, A. J., J. Gokhale, and L. J. Kotlikoff, 1994, "Generational Accounting: A Meaningful Way to Evaluate Fiscal Policy", Journal of Economic Perspectives 8, 73-94.

Auerbach, A. J. and L. J. Kotlikoff, 1987, Dynamic Fiscal Policy, Cambridge University Press.

Ball, L. and N. G. Mankiw, 2007, "Intergenerational Risk Sharing in the Spirit of Arrow, Debreu, and Rawls, with Applications to Social Security Design", Journal of Political Economy 115, 523-547.

Barro, R. J., 2006, "Rare Disasters and Asset Markets in the Twentieth Century", The Quarterly Journal of Economics 121, 823-866.

Bodie, Z., R. C. Merton, and W. F. Samuelson, 1992, "Labor Supply Flexibility and Portfolio Choice in a Life Cycle Model", Journal of Economic Dynamics and Control 16, 427-449.

Bohn, H., 1998, "Risk Sharing in a Stochastic Overlapping Generations Economy", University of California at Santa Barbara, Economics Working Paper Series, Department of Economics, UC Santa Barbara.

Bohn, H., 1999, "Should the Social Security Trust Fund Hold Equities?: An Intergenerational Welfare Analysis", Review of Economic Dynamics 2, 666-697.

Bohn, H., 2001, "Social Security and Demographic Uncertainty: The Risk-Sharing Properties of Alternative Policies", in J. Campbell and M. Feldstein, editors, "Risk Aspects of Investment Based Social Security Reform", Chicago: University of Chicago Press, 203-241.

Bohn, H., 2002, "Retirement Savings in an Aging Society: A Case for Innovative Government Debt Management", in A. Auerbach and H. Herrman, editors, "Ageing, Financial Markets and Monetary Policy", Berlin: Springer, 139-181. 
Bohn, H., 2006, "Who Bears What Risk? An Intergenerational Perspective", in D. Blitzstein, O. S. Mitchell, and S. P. Utkus, editors, "Restructuring Retirement Risks", Oxford, UK: Oxford University Press, 10-36.

Bohn, H., 2009, "Intergenerational Risk Sharing and Fiscal Policy", Journal of Monetary Economics 56, 805-816.

Bovenberg, L. and H. Uhlig, 2008, "Pension Systems and the Allocation of Macroeconomic Risk", in "NBER International Seminar on Macroeconomics 2006", National Bureau of Economic Research, 241-344.

Chatterjee, S., D. Corbae, M. Nakajima, and J.-V. Rios-Rull, 2007, "A Quantitative Theory of Unsecured Consumer Credit with Risk of Default", Econometrica 75, 1525-1589.

Chen, C. and O. Mangasarian, 1996, "A Class of Smoothing Functions for Nonlinear and Mixed Complementarity Problems", Computational Optimization and Applications 5, 97138.

Constantinides, G. M., J. B. Donaldson, and R. Mehra, 2002, “Junior Can’t Borrow: A New Perspective On the Equity Premium Puzzle", The Quarterly Journal of Economics 117, 269-296.

Cooley, T. and E. Prescott, 1995, "Economic Growth and Business Cycles", in "Frontiers of Business Cycle Research", Princeton University Press.

Davis, S. J. and P. Willen, 2000, "Using Financial Assets to Hedge Labor Income Risks: Estimating the Benefits", Working Paper.

Diamond, P., 1977, "A Framework for Social Security Analysis", Journal of Public Economics $8,275-298$.

Fernandez-Corugedo, E., 2002, "Soft Liquidity Constraints and Precautionary Saving", Working paper, Bank of England.

Gomme, P., R. Rogerson, P. Rupert, and R. Wright, 2005, "The Business Cycle and the Life Cycle", NBER Macroeconomics Annual 19.

Goodfriend, M., 2005, Models and Monetary Policy: Research in the Tradition of Dale Henderson, Richard Porter, and Peter Tinsley, chapter Narrow Money, Broad Money, and the Transmission of Monetary Policy, Board of Governors of the Federal Reserve System. 
Goodfriend, M. and B. T. McCallum, 2007, "Banking and Interest Rates in Monetary Policy Analysis: A quantitative exploration", Journal of Monetary Economics 54, 1480-1507.

Gourinchas, P.-O., 2000, "Precautionary Savings, Life Cycle and Macroeconomics", Econometric Society World Congress 2000 Contributed Papers 0793, Econometric Society.

Green, J. and L. J. Kotikoff, 2008, "On the General Relativity of Fiscal Language", in A. J. Auerbach and D. N. Shaviro, editors, "Institutional Foundations of Public Finance", Cambridge: Harvard University Press, 241-256.

Hansen, G. D., 1985, "Indivisible Labor and the Business Cycle", Journal of Monetary Economics 16, 309-327.

Harenberg, D. and A. Ludwig, 2016, "Idiosyncratic Risk, Aggregate Risk, and the Welfare Effects of Social Security", SAFE working paper no. 59. Available at SSRN: https://ssrn.com/abstract $=2464170$.

Hasanhodzic, J., 2014, "Increasing Borrowing Costs and the Equity Premium", SSRN working paper. Available at SSRN: https://ssrn.com/abstract=2425330.

Hasanhodzic, J. and L. Kotlikoff, 2013, "Generational Risk-Is It a Big Deal?: Simulating an 80-Period OLG Model with Aggregate Shocks", NBER Working Papers 19179, National Bureau of Economic Research.

Hasanhodzic, J., A. W. Lo, and P. Patel, 2009, "The CS 130/30 Index: A Summary and Performance Comparison", White paper, Credit Suisse.

Hayashi, F., 1987, "Tests for Liquidity Constraints: A Critical Survey and Some New Observations", in F. T. Bewley, editor, "Advances in Econometrics, Fifth World Congress", Cambridge University Press, Cambridge, England.

Jagannathan, R., E. McGrattan, and A. Scherbina, 2000, "The Declining U.S. Equity Premium", Federal Reserve Bank of Minneapolis Quarterly Review 24, 3-19.

Judd, K., L. Maliar, and S. Maliar, 2009, "Numerically Stable Stochastic Simulation Approaches for Solving Dynamic Economic Models", NBER Working Papers 15296, National Bureau of Economic Research.

Judd, K., L. Maliar, and S. Maliar, 2011, "Numerically Stable Stochastic Simulation Approaches for Solving Dynamic Economic Models", Quantitative Economics 2, 173-210. 
Krueger, D. and F. Kubler, 2004, "Computing Equilibrium in OLG Models with Stochastic Production", Journal of Economic Dynamics and Control 28, 1411-1436.

Krueger, D. and F. Kubler, 2006, "Pareto-Improving Social Security Reform when Financial Markets are Incomplete!?", American Economic Review 96, 737-755.

Krusell, P. and A. A. Smith, 1997, "Income And Wealth Heterogeneity, Portfolio Choice, And Equilibrium Asset Returns", Macroeconomic Dynamics 1, 387-422.

Krusell, P. and A. A. Smith, 1998, "Income and Wealth Heterogeneity in the Macroeconomy", Journal of Political Economy 106, 867-896.

Krusell, P. and A. A. Smith, 1999, "On the Welfare Effects of Eliminating Business Cycles", Review of Economic Dynamics 2, 245-272.

Lucas, R., 1987, Models of Business Cycles, Oxford, UK: Basil Blackwell.

Malin, B. A., D. Krueger, and F. Kubler, 2011, "Solving the Multi-Country Real Business Cycle Model Using a Smolyak-Collocation Method", Journal of Economic Dynamics and Control 35, 229-239.

Marcet, A., 1988, "Solution of Nonlinear Models by Parameterizing Expectations", Technical report, Carnegie Mellon University.

Marcet, A. and G. Lorenzoni, 2001, "The Parameterized Expectations Approach: Some Practical Issues", in R. Marimon and A. Scott, editors, "Computational Methods for the Study of Dynamic Economies", Chicago: Oxford University Press.

Marcet, A. and D. A. Marshall, 1994, "Solving Nonlinear Rational Expectations Models By Parametrized Expectations: Convergence to Stationary Solutions", Discussion paper 91, Federal Reserve Bank of Minneapolis.

Mehra, R., 2008, "The Equity Premium Puzzle: A Review", Foundations and Trends in Finance 2, 1-81.

Merton, R. C., 1983, "On the Role of Social Security as a Means for Efficient Risk-Bearing in an Economy Where Human Capital Is Not Tradeable", in Z. Bodie and J. Shoven, editors, "Financial Aspects of the United States Pension System", Chicago: University of Chicago Press.

Milde, H. and J. G. Riley, 1988, "Signaling in Credit Markets", Quarterly Journal of Economics 103, 101-129. 
Prescott, E., 1986, "Theory Ahead of Business-Cycle Measurement", Carnegie-Rochester Conference Series on Public Policy 25, 11-44.

Rangel, A. and R. Zeckhauser, 2001, "Can Market and Voting Institutions Generate Optimal Intergenerational Risk Sharing?", in "Risk Aspects of Investment-Based Social Security Reform", NBER Chapters, National Bureau of Economic Research, 113-152.

Rawls, J., 1971, A Theory of Justice, Cambridge, MA: Belknap Press of Harvard University Press.

Reiter, M., forthcoming, "Solving OLG Models with Many Cohorts, Asset Choice and Large Shocks", personal correspondence.

Rietz, T. A., 1988, "The Equity Risk Premium: A Solution", Journal of Monetary Economics $22,117-131$.

Rios-Rull, J. and R. Santaeulalia-Llopis, 2010, "Redistributive Shocks and Productivity Shocks", Journal of Monetary Economics 57, 931-948.

Rios-Rull, J.-V., 1994, "On the Quantitative Importance of Market Completeness", Journal of Monetary Economics 34, 463-496.

Rios-Rull, J.-V., 1996, "Life-Cycle Economies and Aggregate Fluctuations", Review of Economic Studies 63, 465-489.

Shiller, R., 1999, "Social Security and Intergenerational, Intragenerational, and International Risk Sharing", Carnegie-Rochester Conference Series on Public Policy 50, 165-204.

Siegel, J. J., 1998, Stocks for the Long Run: The Definitive Guide to Financial Market Returns and Long-Term Investment Strategies, McGraw-Hill.

Smetters, K. A., 2003, "Trading with the Unborn: A New Perspective on Capital Income Taxation", NBER Working Papers 9412, National Bureau of Economic Research.

Storesletten, K., C. Telmer, and A. Yaron, 2007, "Asset Pricing with Idiosyncratic Risk and Overlapping Generations", Review of Economic Dynamics 10, 519-548.

Weitzman, M. L., 2007, "Subjective Expectations and Asset-Return Puzzles", American Economic Review 97, 1102-1130.

Wirjanto, T. S., 1995, "Aggregate Consumption Behaviour and Liquidity Constraints: The Canadian Evidence", Canadian Journal of Economics 28, 1135-1152. 


\section{A Appendix}

\section{For Online Publication}

\section{A.1 Algorithm}

The following is a step-by-step description of our algorithm.

\section{Initialization:}

- Set $\bar{z}$ and $\bar{\delta}$ to their average values and solve for the nonstochastic steady state cash on hand of each age group without bond, $\bar{s}=\left(\bar{x}_{1}, \ldots, \bar{x}_{G-1}\right)$. Let $\left(s_{0}, z_{0}, \delta_{0}\right)=(\bar{s}, \bar{z}, \bar{\delta})$ be the starting point of the simulation.

- Approximate $G-1$ consumption functions by polynomials in the state variables and the shock delta: $c_{1}(s, z, \delta)=\phi_{1}\left(s, z, \delta ; b_{1}\right), \ldots, c_{G-1}(s, z, \delta)=\phi_{G-1}\left(s, z, \delta ; b_{G-1}\right)$, where $b_{1}, \ldots, b_{G-1}$ are polynomial coefficients. We use linear polynomials. To start the iterations, we make the following initial guess for the coefficients:

$$
b_{1}=\left(0,0.9 \bar{c}_{1} / \bar{x}_{1}, 0, \ldots, 0,0.1 \bar{c}_{1}, 0\right), \ldots, b_{G-1}=\left(0,0, \ldots, 0,0.9 \bar{c}_{G-1} / \bar{x}_{G-1}, 0.1 \bar{c}_{G-1}, 0\right) \text {. }
$$

- Take draws of the exogenous path of shocks for $T$ years. We set $T$ to 830, which corresponds to roughly 10 observations per polynomial coefficient.

\section{Outer loop:}

- The first step in the outer loop is to simulate the model forward, i.e. compute the state space for $t=1, \ldots, T$. To do so, at each time $t$ we proceed as follows:

- Recall that at time $t$, the state vector consists of the vector of cash-on-hand variables of generations 1 through $G-1, s_{t}=\left(x_{1, t}, \ldots, x_{G-1, t}\right)$ and exogenous shocks.

- Using this state vector, for each age group $g$, calculate its consumption $c_{g}^{(p)}$ given the current guess for the coefficients $b_{g}^{(p)}$, where the subscript $(p)$ denotes the current iteration of the outer loop. I.e., $c_{g, t}^{(p)}$ equals the inner product of the vector $\left(1, s_{t}, z_{t}, \delta_{t}\right)$ with the vector of coefficients $b_{g}^{(p)}$. Compute the generation-specific asset demands, $\theta_{g, t}$, as the difference between cash on hand and consumption, $\theta_{g, t}=x_{g, t}-c_{g, t}$. Note that the sum of asset demands of generations 1 through $G-1$ is the capital stock at the beginning of period $t+1, k_{t+1}$. 
- At this point enter the inner loop to compute the agents' choices of bond shares, $\alpha_{g, t}$, for generations 1 through $G-1$, and the risk free rate $\bar{r}_{t}$. Recall that these are needed to compute the cash-on-hand variables at time $t+1$.

- Inner loop:

* Use Broyden's method to solve (8) for $\bar{r}_{t}$. To start, make an (arbitrary) initial guess for the value of $\bar{r}_{t}$.

* Given $\bar{r}_{t}$, solve the system of $G-1$ equations given by (19) for $g=1, \ldots, G-1$, for $G-1$ unknowns, $\alpha_{1, t}, \ldots, \alpha_{G-1, t}$. To do so, approximate the expectation by Gaussian quadrature. ${ }^{30}$ Notice that the consumption at time $t+1, c_{g, t+1}$, on the right-hand-side of each equation (19) needs to be approximated by the polynomial in the state vector plus $\delta$. Hence, each of these equations depends on the entire distribution of the cash-on-hand variables, and through them, on all of the generation-specific $\alpha$ 's, $\alpha_{1, t}, \ldots, \alpha_{G-1, t}$. To solve a nonlinear system of $G-1$ nonlinear equations in $G-1$ unknowns we use the GaussSeidel algorithm, which reduces the problem of solving for $G-1$ unknowns simultaneously in $G-1$ equations to that of iteratively solving $G-1$ equations in one unknown. ${ }^{31}$ We solve each of these nonlinear equations in one unknown $\alpha$ using Newton's method.

* Use $\alpha_{g, t}$ found above for all $g$ to calculate (8) and update $\bar{r}_{t}$.

- Given $\alpha_{g, t}$ for $g=1, \ldots, G-1, \bar{r}_{t}, k_{t+1}$, and exogenous shocks, we can now compute each generation's cash on hand in period $t+1$ as the sum of their labor and capital income (plus or minus any government transfers) at time $t+1$.

- Note that for each age group $g$ and each state $\left(s_{t}, z_{t}\right), t=1, \ldots, T,(18)$ implies

$$
\begin{aligned}
c_{g}(s, z) & =\left\{\beta E_{z}\left[\left(1+r\left(s^{\prime}, z^{\prime}\right)\right) u^{\prime}\left(c_{g+1}\left(s^{\prime}, z^{\prime}\right)\right)\right]\right. \\
& \left.+I \beta E_{z}\left[\left(\alpha_{g}(s, z)\left(\bar{r}(s, z)-r\left(s^{\prime}, z^{\prime}\right)\right)-f\left(\alpha_{g}(s, z)\right)\right) u^{\prime}\left(c_{g+1}\left(s^{\prime}, z^{\prime}\right)\right)\right]\right\}^{-\frac{1}{\gamma}} .
\end{aligned}
$$

Denote the right-hand-side of (A.1) by $y_{g}$ and evaluate the expectation using Gaussian quadrature.

- For each age group $g$, regress $y_{g}$ on $\left(s_{t}, z_{t}, \delta_{t}\right)$ and a constant term using regularized least

\footnotetext{
${ }^{30}$ We use 4 nodes in the quadrature, using more does not change the results.

${ }^{31}$ As the starting point for Gauss-Seidel we use the $\alpha$ 's computed at time t- 1 .
} 
squares with Trikhonov regularization. Denote the estimated regression coefficients by $\hat{b}_{g}^{(p)}$.

- Check for convergence: If

$$
\frac{1}{G-1} \sum_{g=1}^{G-1} \frac{1}{T} \sum_{t=1}^{T}\left|\frac{x_{g}^{(p-1)}-x_{g}^{(p)}}{x_{g}^{(p-1)}}\right|<\epsilon
$$

end. Otherwise, for each age group $g$ update the coefficients as $b_{g}^{(p+1)}=(1-\xi) b_{g}^{(p)}+\xi \hat{b}_{g}^{(p)}$ and return to the beginning of the outer loop. We use $\xi=0.1$ and $\epsilon \in\left[10^{-7}, 10^{-13}\right]$.

\section{A.1.1 Accuracy Test Results}

We now present the results of the two accuracy tests (out-of-sample deviations from the exact satisfaction of the Euler equations and the Den Haan-Marcet statistic) described and summarized in Sections 5.1 and 5.2.

\section{A.2 Generational Risk-Inducing Policy}

To ensure that our generational risk measures are, indeed, capturing generational risk, we next simulate our base model, but with risk-inducing policy and with depreciation shocks turned off to maximize the policy's ability to exacerbate TFP shocks. In considering this policy, bear in mind that it tends to persist because it's tied to the wage, which is tied to TFP, whose process is autocorrelated.

By construction, the risk-inducing policy differentially affects the young and old. It does so by making the good times far less good for the young and far better for the old. For example, if $\mathrm{z}$ and the capital stock are kept at their average values, the young receive a wage of 1.657, pay 0.366 in taxes, and the old receive 0.471 in benefits. If times are good and $\mathrm{z}$ is two standard deviations above the mean, the corresponding values are 1.761 for the wage, 0.503 for the tax on the young, and 0.647 for the old-age benefit. If times are bad and $\mathrm{z}$ is two standard deviations below the mean, the wage, tax, and benefit amounts are now 1.553, 0.229 , and 0.295 , respectively. Notice that in this example, if viewed as the percentage of the wage, the tax on the young is almost twice as large in the good state than in the bad state. On the other hand, the old receive a benefit in the good state that is more than twice as large than that in the bad state, while also enjoying a higher return on their investments.

The younger young and the older old are particularly affected. Indeed, we would expect smaller correlations in percentage changes in consumption the further apart are agents in age. Table A.3, which considers age group two, shows that this is precisely what happens. 
Mean Absolute Euler Equation Deviations

\begin{tabular}{|c|c|c|c|}
\hline & Min & Mean & $\operatorname{Max}$ \\
\hline & \multicolumn{3}{|c|}{ Base Model } \\
\hline No Social Security & 0.0000 & 0.0002 & 0.0005 \\
\hline \multirow[t]{2}{*}{ Social Security } & 0.0001 & 0.0003 & 0.0005 \\
\hline & \multicolumn{3}{|c|}{ Base Model With Borrowing Costs } \\
\hline No Social Security & 0.0002 & 0.0013 & 0.0031 \\
\hline \multirow[t]{2}{*}{ Social Security } & 0.0004 & 0.0009 & 0.0018 \\
\hline & \multicolumn{3}{|c|}{ Base Model Without Bonds } \\
\hline No Social Security & 0.0000 & 0.0002 & 0.0003 \\
\hline \multirow[t]{2}{*}{ Social Security } & 0.0001 & 0.0003 & 0.0006 \\
\hline & \multicolumn{3}{|c|}{ Alternative Model } \\
\hline No Social Security & 0.0009 & 0.0024 & 0.0039 \\
\hline \multirow[t]{2}{*}{ Social Security } & 0.0013 & 0.0026 & 0.0039 \\
\hline & \multicolumn{3}{|c|}{ Alternative Model Without Bonds } \\
\hline No Social Security & 0.0012 & 0.0016 & 0.0018 \\
\hline \multirow[t]{2}{*}{ Social Security } & 0.0015 & 0.0022 & 0.0027 \\
\hline & \multicolumn{3}{|c|}{ Risk-Inducing Policy } \\
\hline Bond Market & 0.0000 & 0.0001 & 0.0005 \\
\hline \multirow[t]{2}{*}{ No Bond Market } & 0.0000 & 0.0000 & 0.0002 \\
\hline & \multicolumn{3}{|c|}{ Sensitivity Analysis Models } \\
\hline More Volatile TFP & 0.0000 & 0.0006 & 0.0011 \\
\hline More Persistent TFP & 0.0000 & 0.0001 & 0.0001 \\
\hline Very High Risk Aversion & 0.0000 & 0.0000 & 0.0000 \\
\hline
\end{tabular}

Table A.1: Minimum, mean, and maximum across generations of the average, across time, of the absolute value of the generation-specific, out-of-sample deviations from the perfect satisfaction of Euler equations.

The Den Haan-Marcet Statistic

\begin{tabular}{l|rrr}
\hline & Min & Mean & Max \\
& \multicolumn{3}{c}{ Base Model } \\
No Social Security & 6.240 & 12.292 & 21.285 \\
Social Security & 12.315 & 18.310 & 24.828 \\
& \multicolumn{4}{c}{ Alternative Model } \\
No Social Security & 5.506 & 10.837 & 23.188 \\
Social Security & 5.598 & 10.184 & 16.851 \\
\hline
\end{tabular}

Table A.2: The minimum, mean, and maximum values across generations of the Den Haan-Marcet statistic in the base and alternative models. 
Correlations of Age Group Two's Percent Changes in Consumption with Those of Other Age Groups No Stochastic Depreciation and No Bond Market

\begin{tabular}{|c|c|c|c|c|c|c|c|c|c|c|}
\hline Age group 2 correlated with age & 3 & 25 & 34 & 35 & 36 & 37 & 38 & 39 & 55 & 80 \\
\hline Correlation & 1.000 & 0.998 & 0.921 & 0.806 & 0.419 & -0.330 & -0.731 & -0.864 & -0.976 & -0.979 \\
\hline
\end{tabular}

Table A.3: Correlations of age group two's percent changes in consumption with percent changes in consumption of other age groups.

Bohn, in several papers, and Bovenberg and Uhlig (2008) consider a different generationalrisk producing policy namely one that raises Social Security's tax rate in bad times (negative TFP shocks) and lower it in good times (positive TFP shocks) to maintain benefit levels. This, obviously, makes bad (good) times worse (better) for workers while protecting retirees' benefits.

\section{Measures of Generational Risk With Risk-Inducing Policy No Stochastic Depreciation, With and Without Bond Market}

\begin{tabular}{lccccccc}
\hline & \multicolumn{3}{c}{ No Bond Market } & \multicolumn{3}{c}{ Bond Market } \\
& Min & Mean & Max & Min & Mean & Max \\
& -0.973 & 0.374 & 1.000 & 1.000 & 1.000 & 1.000 \\
corr(\% change in C worker i; \% change in C worker j) & 0.996 & 0.999 & 1.000 & 0.996 & 1.000 & 1.000 \\
corr(\% change in C retiree i; \% change in C retiree j) & -0.979 & 0.032 & 1.000 & 0.995 & 1.000 & 1.000 \\
corr(\% change in C agent i; \% change in C agent j) & -0.976 & 0.125 & 0.986 & 0.989 & 0.995 & 0.995 \\
corr(\% change in C agent i; \% change in per capita C) & 0.000 & 0.892 & 7.337 & 0.322 & 0.563 & 0.834 \\
all agents: absolute \% adjustment for perfect risk sharing & 0.03 & & & & & &
\end{tabular}

Table A.4: Measures of generational risk with risk-inducing policy with and without bonds. The measures are presented as summary statistics of pairwise correlations in percentage changes in consumption among different age groups (first four rows) and absolute percentage adjustments needed to achieve full risk sharing (last row).

Table A.4, which incorporates the risk-inducing policy, reports summary statistics of pairwise correlations in annual percentage changes in consumption between different age groups among workers only, retirees only, and all agents. ${ }^{32}$ Second, it examines the correlation of each agent's annual percentage change in consumption with the annual percentage change in per capita consumption. And third, it reports the absolute percent adjustments to achieve perfect risk sharing among contemporaneous generations in the base model, analogous to the results in Table 4 for the base model with Social Security. The results that are dramatically different from those for the base model. Take row 4, for example, which shows the minimum, mean, and maximum values of the correlation of each agent's percentage change

\footnotetext{
${ }^{32}$ For each age group pair, $g$ and $g^{\prime}$, we correlate the pair's percentage consumption changes between adjacent time periods across all 755 time periods during which they overlap. Hence, each correlation coefficient is calculated based on the same number of observations.
} 
in consumption with per capita consumption. These three values, in the no-bond-market case, are $-0.976,0.125$, and 0.986 . Recall that in the base case, the corresponding values all equal 0.9 rounded to one decimal place. Hence, we see what we expect-larger measured generational risk in the presence of larger generational risk.

The addition of bonds reverses this story. With bonds, the Table-A.4, row-4 values are 0.989, 0.995, and 0.995, indicating, as before, that in principle the bond market can be effective in hedging generational risk. This is also clear from the last row in Table A.4. Without bonds, the maximum adjustment needed to achieve full risk sharing among living generations is 7.337 percent. With bonds, it's far less, 0.834 percent.

\section{A.3 Sensitivity Analysis}

To assess the robustness of our findings, we also simulate models with high risk aversion, greater persistence of the TFP shocks or larger TFP shocks. Specifically, we consider risk aversion of 15, a TFP process with an annual autocorrelation coefficient of 0.961 (recall, the base model's annual value is 0.814 ), and a TFP shock whose standard deviation is 5 times larger than in the base model. All models feature a bond market and no depreciation shocks or Social Security. Table A.5 shows that increasing risk aversion to 15 has minimal effect on both output variability and generational risk. On the other hand, increasing the volatility or the persistence of the TFP process increases our realized utility measure of generational risk. Table A.6 shows that this coincides with an increase in the variability of output (and, thus, wages) beyond empirically relevant values. Table A.7 shows that each of the above variants confirms our finding in sections 6.2 and 6.3 of very small generational risk across contemporaneous generations in the presence of the bond market. The bond market, even though its maturity is only one period, is remarkably robust in pooling risk among contemporaneous generations. 


$\begin{gathered}\text { Absolute Percent Adjustment to Achieve Average } \\ \text { Realized Utility of Newborns Through Time }\end{gathered}$
Models With More Volatile or Persistent TFP or Higher
Risk Aversion

Table A.5: Means and standard deviations of absolute percentage adjustments needed to achieve average realized utility of newborns through time. All models feature a bond market and no depreciation shocks or Social Security.

\section{Standard Deviation of Output Percent Deviations from the Mean}

\begin{tabular}{lcr}
\hline \multicolumn{1}{c}{ Model } & $\begin{array}{c}\text { Risk } \\
\text { Aversion }\end{array}$ & $\begin{array}{c}\text { Standard } \\
\text { Deviation (\%) }\end{array}$ \\
Base model & 15 & 3.662 \\
More persistent TFP & 2 & 8.739 \\
More volatile TFP & 2 & 18.644 \\
\hline
\end{tabular}

Table A.6: Standard deviation of percentage deviations from the mean in output, with high risk aversion, with higher persistence, or higher volatility in the TFP process. When the TFP process is more persistent, its autocorrelation coefficient equals 0.99 on a quarterly basis (0.96 on an annual basis). When it is more volatile, the standard deviation of its innovation is 5 times larger than that assumed in the base model. All models include bonds and do not include depreciation shocks. 
Generational Risk With More Volatile or More Persistent TFP Process, and High Risk Aversion

\begin{tabular}{|c|c|c|c|c|c|c|}
\hline & \multicolumn{3}{|c|}{$\begin{array}{l}\text { Assumed TFP } \\
\text { Risk aversion } 15\end{array}$} & \multicolumn{3}{|c|}{$\begin{array}{c}\text { More persistent TFP } \\
\text { Risk aversion } 2\end{array}$} \\
\hline & Min & Mean & Max & Min & Mean & $\operatorname{Max}$ \\
\hline corr $(\%$ change in $\mathrm{C}$ worker $\mathrm{i} ; \%$ change in $\mathrm{C}$ worker $\mathrm{j})$ & 1.000 & 1.000 & 1.000 & 1.000 & 1.000 & 1.000 \\
\hline corr $(\%$ change in $\mathrm{C}$ retiree $\mathrm{i} ; \%$ change in $\mathrm{C}$ retiree $\mathrm{j}$ ) & 1.000 & 1.000 & 1.000 & 1.000 & 1.000 & 1.000 \\
\hline corr $(\%$ change in $\mathrm{C}$ agent $\mathrm{i} ; \%$ change in $\mathrm{C}$ agent $\mathrm{j}$ ) & 1.000 & 1.000 & 1.000 & 1.000 & 1.000 & 1.000 \\
\hline corr $(\%$ change in $\mathrm{C}$ agent $\mathrm{i} ; \%$ change in per capita $\mathrm{C})$ & 0.997 & 0.997 & 0.997 & 0.999 & 0.999 & 0.999 \\
\hline \multirow[t]{3}{*}{ all agents: absolute $\%$ adjustment for perfect risk sharing } & 0.000 & 0.036 & 0.092 & 0.005 & 0.129 & 0.234 \\
\hline & \multicolumn{3}{|c|}{$\begin{array}{l}\text { More volatile TFP } \\
\text { Risk aversion } 2\end{array}$} & \multicolumn{3}{|c|}{$\begin{array}{c}\text { Assumed TFP } \\
\text { Risk aversion } 2\end{array}$} \\
\hline & Min & Mean & Max & Min & Mean & Max \\
\hline corr $(\%$ change in $\mathrm{C}$ worker $\mathrm{i} ; \%$ change in $\mathrm{C}$ worker $\mathrm{j}$ ) & 1.000 & 1.000 & 1.000 & 1.000 & 1.000 & 1.000 \\
\hline $\operatorname{corr}(\%$ change in $\mathrm{C}$ retiree $\mathrm{i} ; \%$ change in $\mathrm{C}$ retiree $\mathrm{j})$ & 1.000 & 1.000 & 1.000 & 1.000 & 1.000 & 1.000 \\
\hline $\operatorname{corr}(\%$ change in $\mathrm{C}$ agent $\mathrm{i} ; \%$ change in $\mathrm{C}$ agent $\mathrm{j}$ ) & 0.999 & 1.000 & 1.000 & 1.000 & 1.000 & 1.000 \\
\hline corr $(\%$ change in $\mathrm{C}$ agent $\mathrm{i} ; \%$ change in per capita $\mathrm{C})$ & 0.998 & 0.999 & 0.999 & 0.999 & 0.999 & 0.999 \\
\hline all agents: absolute $\%$ adjustment for perfect risk sharing & 0.000 & 0.133 & 0.495 & 0.076 & 0.129 & 0.176 \\
\hline
\end{tabular}

Table A.7: Measures of generational risk in the model with high risk aversion, or with high persistence or volatility in the TFP process. All models feature a bond market, no depreciation shocks, and no Social Security. The measures of generational risk include summary statistics of pairwise correlations in percentage changes in consumption among different age groups (first four rows) and absolute percentage adjustments needed to achieve full risk sharing (last row). 